cher Tinte angefertigte Schrift wurde ein Jahr lang der Luft und den Sonnenstrahlen ausgesetzt, obne dass nachher die geringste Veränderung davon wahrzunehmen gewesen wäre, während die Schrift, die mit andern Tintenarten, oder mit Tinten, in denen das Verhältniss der Bestandtheile ein anderes, wie oben gemacht worden, unter gleichen Umständen mehr oder weniger verändert wurde. Endlich setzt diese Tinte keinen Niederschlag des darin enthaltenen Eisen-Gallotanats ab, was zu der Dauerhaftigkeit der Schriftzüge wesentlich beiträgt.

Tinten, in denen ein Theil der Galläpfel durch Campechenholz ersetzt wird, sind weniger dauerhaft, als die nur aus Galläpfeln bereiteten.

Das passendste Mittel, die Schwärze der Tinte möglichst zu erböhen, fand Starck in der Indigolösung. Wird diese gewöhnlicher Eisentinte in einem angemessenen Verhältnisse zugesetzt, so erhält man eine Flüssigkeit, welche leicht aus der Feder fliesst, und nicht absetzt. Die damit gemachten Schriftziige sind frisch auf dem Papiere gut sichtbar, zeigen trocken eine tief schöne Schwärze, und verblassen niemals.

Nach Starck ist folgende Vorschrift die beste:

Galläpfel ......... 375 Theile

Indigolösung $\ldots \ldots \ldots \ldots 250$ n

Grüner Eisenvitriol .....250

Arabisches Gummi ...... $125-180$ Th.

Gewürznelken .......... 2 Theile

Wasser so viel, als erforderlich, um $2000 \mathrm{Th}$. Tinte zu erhalten.

Schliesslich emptiehit Starck zur Anfertigung wichtiger Schriftstïcke den Gebrauch der Gänsefeder, da durch die Berührung mit der Metallfeder auch die beste Tinte in ihrer Dauerhaftigkeit mehr oder weniger beein. trächtigt wird. (Journ. of the Franklin Instit. - Journ. de Pharm. et de Chim. Octbr. 1859. pag. 283 etc.) Hendess.

\title{
Veber eine neue Methode der Bleiweissfabrikation und über eine Ursache des Vergelbens der Bleiweissanstriche.
}

Dr. Grüneberg bringt gekörntes Blei in horizontal um ihre Achse rotirenden sechsseitigen Cylindern von Thon in Bewegung, während gleichzeitiger Einwirkung von Luft, Essigsäure und Kohlensäure, wobei Luftund Kohlensäure durch Oeffnungen im Boden der Cylinder einströmen, Essigsäure und Kohlensäure aber durch 
die hohle Achse eingefïhrt werden. Nach dieser Methode erfolgt die Bleiweissbildung binnen acht Tagen, während die holländische Methode acht Wochen gebraucht, um dasselbe Gewicht Blei in Bleiweiss umzuwandeln.

Das fertige Bleiweiss wird mit dünner Bleizuckerlösung aus den Cylindern ansgespült und bedarf weder des Mahlens noch weiteren Schlämmens. Das genaue Verfahren, das Trocknen des farbigen Bleiweisses in Centrifugal-Apparaten u. s. w. ist in seiner Abhandlung (Monatsschr. des Gewbe.-Vereins in Cöln. 1860. S. 193) speciell angegeben.

Benson und Wollner versetzen Glätte mit 1 Proc. Bleizucker und lassen dies Gemisch in um ihre Achse rotirenden Cylindern von $\mathrm{Holz}$ unter Wasserzusatz und gleichzeitiger Einwirkung ausbrennenden Kalkes entwickelte Kohlensäure in bleiweiss verwandeln.

Dr. Grüneberg dagegen setzt der Glätte noch 50 Proc. gekörntes Blei hinzu, wodurch die Deckkraft des fertigen Bleiweisses bedeutend vermehrt werden soll. Ausserdem verlangt Grüneberg völlige Freiheit der Glätte von Kupfer, da Bleiweiss aus kupferoxydhaltiger Glätte bereitet, Anstriche geben soll, welche sehr bald gelb werden. (Das Gelbwerden der Bleiweissanstriche dürfte auch bei kupferfreiem Vitriol stets statt finden. B.) (Elsner's chem. - techn. Mittheil. des Jahres 1860-61. Berlin 1862.)

Bkb.

\section{Anwendung der antimonigen Săure als weisse Art- strichfarbe.}

Die Herren Dr. John Stenhouse und George Hallett benutzen zur Darstellung der antimonigen Säure das natürliche'Antimonoxyd, welches an verschiedenen Orten von hellgelber bis gelblichrother Farbe vorkommt, gewöhnlich mit Grauspiessglanzerz gemengt, durch dessen mehr oder weniger fortgeschrittene Oxydation es der Meinung der Mineralogen nach, entstanden sein soll. Dasselbe enthält oft Eisenoxyd, Kieselerde und zuweilen auch Arsenik und Wasser. Das natürliche Antimonoxyd wird durch Handscheidung und Schlämmen von seiner Gangart so gut als thunlich befreit und dann durch Mahlen und Sieben in ein feines Pulver verwandelt. Dieses wird in Muffeln oder im Flammofen bei niedriger Rothglühhitze vorsichtig geröstet und dabei zeitweise mit einer Hacke umgerührt. Während des Röstprocesses darf die ange- 